\title{
Fun Mobile-Based Teaching Media for Primary School
}

\author{
Muhammad Irwan Padli Nasution \\ Universitas Islam Negeri Sumatera Utara \\ Medan Indonesia \\ irwannst@uinsu.ac.id
}

\author{
Abdul Hasan Saragih \\ Universitas Negeri Medan \\ Indonesia \\ ahasansaragih@gmail.com
}

\begin{abstract}
Develop mobile devices in Indonesia have penetrated the society of adults to children. Various mobile applications continue would be developed so that the use of mobile devices continues to grow rapidly. Mobile devices such as smartphones and tablets other than as a communication tool can also be developed as a teaching medium, especially, could be developed as an interactive teaching medium that is fun to use in primary school children. Thus, primary school children will be motivated to learn. In designing a fun application, it is necessary to design a proper learning application.
\end{abstract}

Keywords - Fun; mobile-based; teaching; primary school;

\section{INTRODUCTION}

In media education functioned as a means to achieve learning objectives. Because the information contained in the media should be able to involve students, either in the mind or mental as well as in the form of real activity, so that learning can occur. Materials should be designed more systematically and psychologically, and viewed in terms of effective and efficient learning principles.

Learning media should be able to provide a fun experience and meet the individual needs of students, because each student has different abilities. The development of science and technology increasingly encourage renewal efforts in the utilization of technology results in teaching and learning process. Teachers must be able to use the tools that can be provided by the school, and it is possible that the tools are in accordance with the development and the demands of the times. Learning media is anything that can be used to stimulate the mind, feelings, attention and ability or skills of learners so as to encourage the learning process. With the teaching media in the learning process can generate new desires and interests, generate motivation and stimulation of learning activities, and even bring psychological influences on students.

Currently, being booming and already owned by everyone is a smartphone. A smartphone is a mobile phone equipped with various features and specifications are qualified. Smartphones have become one of the phenomena crazy by many people. Smartphones also play an important role in many aspects of human life.
In general, the benefits of media in the learning process is to facilitate the interaction between teachers and students so that learning will be more effective and efficient. Learning media is the physical means to convey the content / learning materials such as: books, movies, videos and so on.[3] Learning media are divided into 10: audio, print, audio-print, silent visual projection, silent audio visual projection, motion, visual, motion visual audio, physical, human and environmental objects and computers. [4]

Each learning medium has certain characteristics, which are linked or viewed from different angles. For example, Schramm looks at the characteristics of the media in terms of economics, the scope of the target that can be covered, and ease of control of the user. Characteristics of the media can also be seen, according to its ability to stimulate all sensory apparatus. In this case, knowledge of the characteristics of instructional media is very important for grouping and selection of media. Media characteristics are the basis of selecting media tailored to specific learning situations.

Renewal of education and teaching has improved both in terms of curriculum, methods and instructional media that aims to form students of quality, creative and able to follow the development of Information and Communication Technology (ICT).

Utilization of educational applications on smartphones or tablets is not new. The Encyclopædia Britannica survey found that 59 percent of older Americans with smartphones / tablets expect schools and educators to invest more in educational applications on both the Android and iOS platforms. They argue that the pattern of learning through applications in this smartphone more interesting. In addition to interactive also more easily stimulate the child to learn. If proper utilization, then the application for smartphones and tablets can be an educational medium that is interesting and fun for children.

\section{PEOPLE, PROCESS, TECHNOLOGY}

At the time of implementation of an information technology system must consider three main aspects, namely People, Process and Technology. In general, usually when the implementation process of ICT systems take place, most organizations are too focused on aspects of technology and so forget the other aspects of people and process. 
If forgotten to the aspect of people and process, it can cause the failure of the ICT system. People are people who have knowledge, manage systems and processes, and are committed to the strategic knowledge process for the whole organization.[2] The educator is the person who is directly face to face with the learners. Thus as good as any and all modern a curriculum and strategic planning of education is designed, if without qualified educators, it will not produce effective results. For that every educator must have some requirements, among is the teaching skills (teaching skills), knowledgeable (knowledgeable), have a professional attitude (attitude professional), choose, create and use the media (utilizing learning media), choose the appropriate teaching method, utilizing technology (utilizing technology), developing a dynamic curriculum, and certainly can provide examples and good practices. In an effort to increase the involvement of learners in the learning process, educators can do so with direct involvement of learners both individually and in groups. By creating opportunities to encourage learners to conduct experiments, engage students or assign tasks to learners from outside sources of class or school and to engage learners in summarizing or concluding learning messages.

There are two important factors that affect the quality and quantity of learner involvement that is internal factors and external factors. Internal factors include physical factors, motivation in learning, interests in the activities provided, intelligence and so forth. While external factors that include educators, learning materials, media, time allocation, facilities and so on. In this study to use the required application of educators who are accustomed.

Process is the arrangement and alignment of strategies, principles, processes, practices to ensure that knowledge management works well when implemented. In this case the process is the process of learning.[2] The learning process is the process of interaction of learners with educators and learning resources in a learning environment. Learning is an aid given by educators in order to occur the process of acquiring knowledge and knowledge, mastery of skills and character, and the formation of attitudes and beliefs in learners. Thus learning is a process to help learners to learn well. Learning while playing and being fun is the right strategy applied to children in elementary school age. This is because elementary school children are still in the world of play, so the proper learning process used is learning while playing and fun. Technology is an important supporting role in knowledge management, requiring competent and confident users when using it. Implementation of the knowledge management system requires a wide range of diverse tools that are involved throughout the technology knowledge cycle used to facilitate communication, collaboration, and content management for knowledge capture, sharing, dissemination and application.[2]

The progress of Information and Communication Technology (ICT) has changed the model and pattern of the process of learning activities in education. In this study used multimedia content by using a mobile device or smartphone android system. Currently the development of android smartphone is very advanced rapidly and can be purchased with a relatively cheap price and easily available in the market freely.

Since its first release, Android has grown very rapidly and further developed and improved into various versions. A unique feature of Android's development is that its versions are named based on different types of food or dessert, which then sorted by alphabet. This unique feature made android versions are easy to remember.

Media classification, and media selection are an integral whole in determining learning strategies. Experts, such as Bretz, Duncan, Briggs, Gagne, Edling, Schramm, and Kemp, have been grouped or taxonomizing the media for learning. Of the grouping, the outline of instructional media can be classified on: graphic media, audio media, silent projection media (visual and audio recording only), and game-simulation mode.

\section{EIGHT GOLDEN RULES}

Characteristics of a good interface should meet the golden rule of eight indicators (eight golden rules) are used as guidelines in designing an interface, namely: [1]

1). Strive for consistency, is a form of maintaining consistency implies the same thing in the same situation as well. For example, a consistency in making menu, font and color, and so forth.

2). Enable frequent users to use shortcuts, a good interface is an interface that maintains general usability such as: common in terms of making abbreviations, hide command and create special keys to perform certain commands.

3). Offer informative feedback, in this case the interface should be able to provide a response to the user feedback is most important from an interface manufacture by reducing uncertainty and always shows the changes that occur when a user interacts with the interface.

4). Design dialogue to yield closure, wherein an interface must have the initial section (intro), the middle (contents), and the final section (cover).

5). Offer simple error handling, the interface must be able to provide an error handler that may be made by the user, the handlers such as by making a menu gray and so forth.

6). Permit easy reversal of action, this feature relieves anxiety, since user knows that errors can be undone; it thus encourages exploration of unfamiliar options. The units of reversibility may be a single action, a data entry, or a complete group of actions.

7). Support internal locus of control, the interface must be able to support the internal control center such as: the interface can respond to the actions of the user, the interface is designed to make the user can become an initiator and not merely as a respondent.

8). Reduce short-term memory load, the final task of a good interface is the interface must be able to reduce the burden of short-term memory for the user. The limitation of human information processing in short-term memory requires 
that displays be kept simple, multiple page displays be consolidated, window-motion frequency be reduced, and sufficient training time be allotted for codes, mnemonics, and sequences of actions.

\section{INTERFACE OVERVIEW}

The interface is designed covers graphical content. Here is design of the menu applications developed:

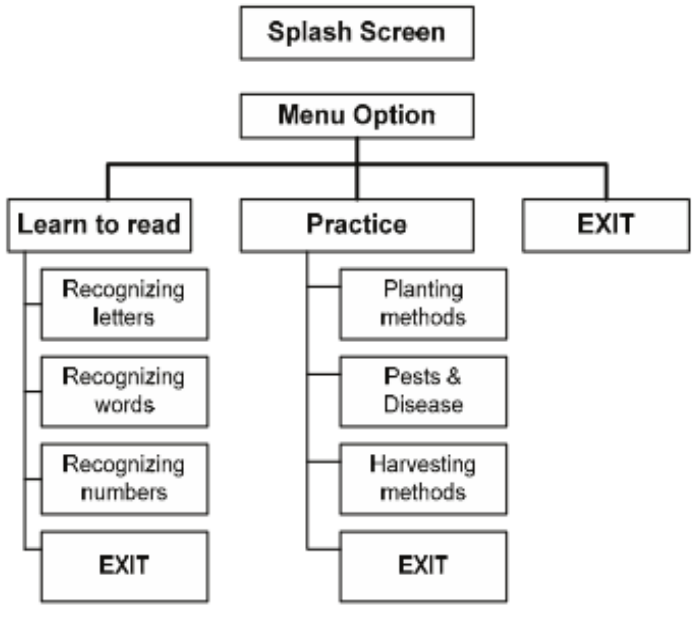

Fig. 1. Main menu design

Main menu design in Figure 1 above were developed and implemented on android with the following views:

\section{Interface for the IIIliterates}

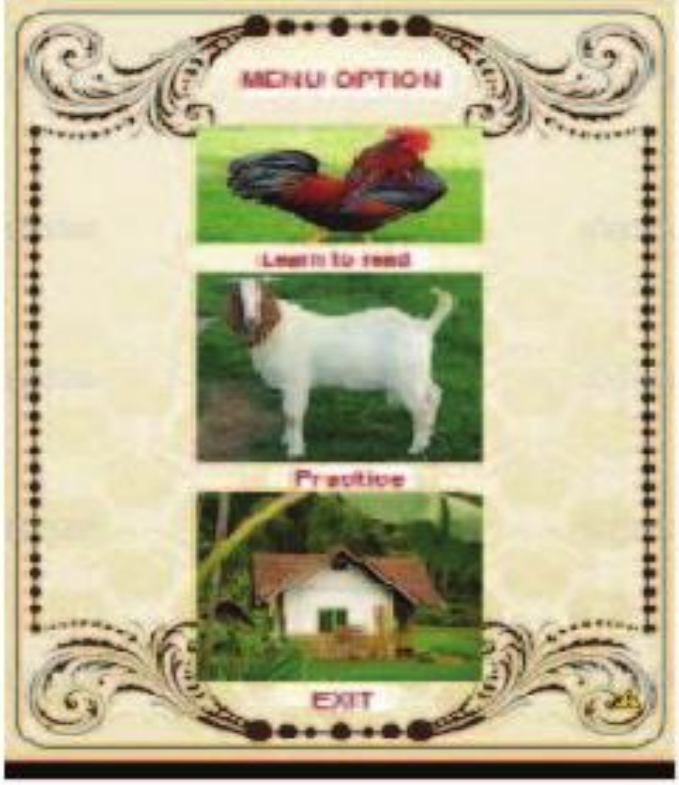

Fig. 2. Main Menu Display

A student who becomes users of this application will then listen to the sounds coming out of the application as a guide to go to the next menu. So to continue to read the menu there will be voice prompts to select the picture chicken. This application is very easy to use because all directions, instructions and explanations made by the interface sounds and images coming out of the application. For example, to recognize the letters $A$, then the sound will come out of the application and the form of the letter A is also displayed, as shown below:provided by the drop down menu to differentiate the head from the text.

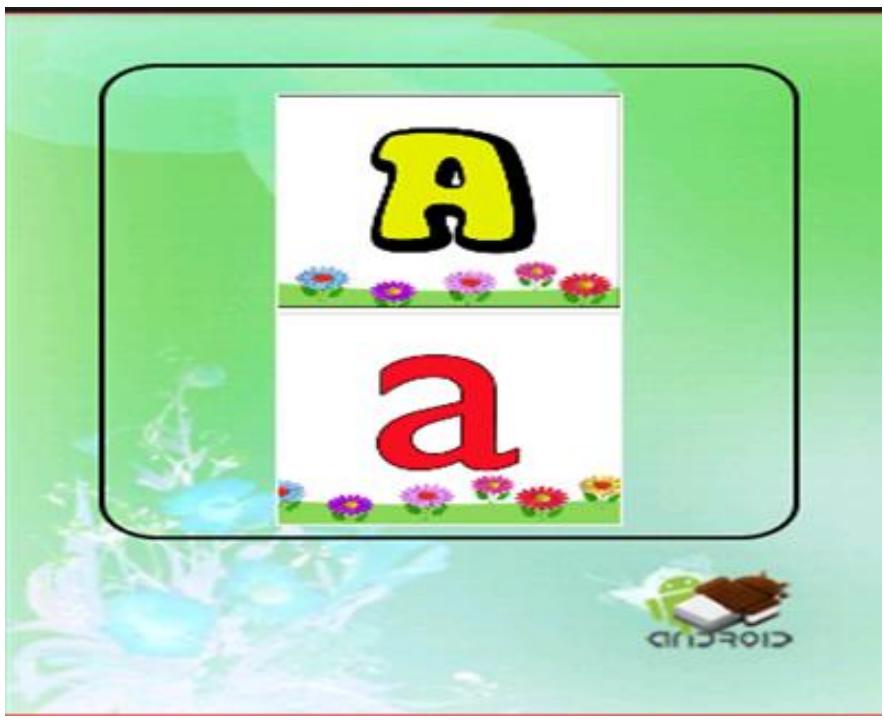

Fig. 3. Display recognize the letters A

\section{CONCLUSION}

Application of the computer application interface for primary school students requires a special approach so that the information can be delivered correctly and clearly. The combination of graphic design and linguistic approach which is then developed with the android based mobile devices, provides added value for students. The combination of these two approaches can help students who will interact with the interface. With applications installed on a mobile device can be used easily and cheaply for primary school. This application requires a small storages capacity and can be installed easily on all mobile devices that use the Android operating system. Thus it can be taken anywhere so student as users can learn wherever they are.

\section{REFERENCES}

[1] B. Shneiderman, C. Plaisant. 2010. "Designing the user interface" Addison Wesley Longman, Inc.

[2] Debowski, Shelda. 2006., Knowledge Management. Melbourne and Sydney: John Wiley and Son Australia, Ltd.

[3] Briggs, Leslie J. 1977. Instructional Design, Educational Technology Publications Inc. New Jersey : Englewood Cliffs.

[4] Anderson,Gary J. 1998, Fundamentals of Educational Research, Psychology Press

[5] Nasution, Muhammad Irwan Padli, 2016, Aplikasi Pembelajaran Berbasis Mobile Untuk Tuna Aksara. MATICS: Journal Of Computer Science and Information Technology, 8 (1). pp. 11-16. ISSN 2477-2550, http://dx.doi.org/10.18860/mat.v8i1.3475 
[6] M. I. P. Nasution, S. Dewi Andriana, P. Diana Syafitri, E. Rahayu and M. R. Lubis, "Mobile device interfaces illiterate," Technology, Informatics, Management, Engineering \& Environment (TIME-E), 2015 International Conference on, Samosir, 2015, pp. 117-120

[7] Nasution, Muhammad Irwan Padli, 2016, Strategi pembelajaran efektif berbasis mobile learning pada sekolah dasar, IQRA': Jurnal Perpustakaan dan Informasi, vol 10, No 1 (2016),
https://www.researchgate.net/publication/305207211_STRATEGI_PEM BELAJARAN_EFEKTIF_BERBASIS_MOBILE_LEARNING_PADA SEKOLAH DASAR 